\title{
Mathematics curriculum development and indigenous language revitalisation: contested spaces
}

\author{
Colleen McMurchy-Pilkington • Tony Trinick • \\ Tamsin Meaney
}

Received: 3 August 2012 / Revised: 30 November 2012 / Accepted: 12 March 2013 /

Published online: 7 April 2013

(C) Mathematics Education Research Group of Australasia, Inc. 2013

\begin{abstract}
This paper examines the development of two iterations of mathematics curricula over a 15-year period for classrooms teaching in te reo Māori, the endangered Indigenous language of Aotearoa New Zealand. Similarities and differences between the two iterations are identified. Although parameters set by the New Zealand Ministry of Education about what the curricula would look like and how they would be developed were not always commensurate with Māori aspirations, analysis suggests that Māori were able to use opportunities to ensure that their agendas for language development and revitalisation were achieved. Spaces were made available because of the government's ideological assumptions, but were used by Māori to achieve their ideological aims. However, neither iteration was smooth, with Māori having to determine how to operate within these contested spaces. The result of Māori requirements to have language recognised as an important issue was that both process and product of curriculum development were affected.
\end{abstract}

Keywords Indigenous mathematics curriculum iterations - Language revitalisation . Walker's model of curriculum development $\cdot$ Contested spaces

\section{Introduction}

In this paper, we examine the contested development of mathematics curricula for schools teaching in the medium of Māori, the Indigenous language of

C. McMurchy-Pilkington $(\bowtie) \cdot T$. Trinick

University of Auckland, Auckland, New Zealand

e-mail: c.mcmurchy@auckland.ac.nz

T. Trinick

e-mail: t.trinick@auckland.ac.nz

T. Meaney

Malmö University, Malmö, Sweden

e-mail: tamsin.meaney@mah.se 
Aotearoa New Zealand, using Walker's (1971) curriculum development model. The development of the first curriculum in the 1990s (New Zealand Ministry of Education 1996) and its revision over a decade later (Te Tahuhu o te Mātauranga 2008), involved contestation around Indigenous knowledge and epistemology, including the modernisation of a mathematics register in te reo Māori, the Māori language. The determination by Māori to revitalise their language saw them take advantage of the opportunities opened up in the curriculum development process, thus making the process an enabling one, despite the heavy contractual constraints placed upon them by the state (McMurchy-Pilkington 2008).

Curriculum development in mathematics is under-researched, even though major curriculum revisions are undertaken about every 10 years in many countries. Often the people allocated to do the revisions have little understanding of what happened during the previous one (Jahnke 2012), making the lack of research problematic. For example, of the 15 papers presented at the Topic Study Group at ICME 12, specifically on curriculum development, only two, an earlier version of this paper and one from Sweden (Jahnke 2012), dealt with the process of developing a curriculum. The rest dealt with curriculum materials, such as textbooks, or the implementation of curricula.

In order to understand how Māori were able to promote language revitalisation as an outcome of curriculum development, it is necessary to examine the material context of the policy construction (Codd 1995). This context embraces the political and economic conditions of curriculum policy development, including the beliefs and values of the state agents and curriculum developers involved. Codd (1995) described such an analysis as a materialist approach. Using a material context approach, the ideologies embedded in the socio-political context need to be recognised as influencing the development process at the macro level (the why and how of curriculum development). Integral to the macro context are the actions and the sometimes conflicting aspirations of the various actors and agencies involved at the micro level, such as state officials, curriculum developers, community, and teachers. Consequently, curriculum development is a politically driven multi-level process where the actors' actions and beliefs have an impact on the end users, the teachers and students.

The circumstances surrounding the development of the two iterations of the Māorimedium mathematics curriculum exemplify why curriculum development is not simply the concern of technical experts with efficient development techniques, but is a site of contestation between the ideologies held by the main actors. Although we do not describe the implementation of the curricula, the outcomes from this contestation did have general implications for learning and teaching in Māori-immersion mathematics classrooms (Trinick forthcoming 2013). As discussed later, one example of the impact on teaching and learning is the ongoing tension between the use of $i w i$ (tribal) dialects and the need for a standardised mathematics vocabulary.

By contrasting two iterations of the development of a mathematics curriculum for schools teaching in the Māori language, we are able to show how different actors' ideologies contributed to the development of mathematic curricula that contributed to the revitalisaton of an Indigenous language. These examples show that the development of these mathematics curricula had linguistic, cultural, and political consequences for the language community and for the language itself. 


\section{Māori-medium education and neo-liberal policies}

Māori are the Indigenous people of Aotearoa New Zealand. However, during the 19th century Pākeha settlers (non-Māori) came to control more and more aspects of New Zealand society and language. Māori language and culture were excluded from schooling by education policies because they were seen as obstacles to the educational and social progress of Māori. Smith (1990) stated that "New Zealand schools are locked into a cycle of social and cultural reproduction of Pākeha culture premised on an imperialistic presumption that Pākeha defined cultural capital as the most appropriate for all New Zealand's peoples" (p. 80, italics in the original). The journey of Māori cultural marginalisation and language loss is similar to that of many other Indigenous peoples worldwide.

By the 1960s, after more than a century of repression, the Māori language was endangered (Fishman 1991) and threatened with possible extinction (Spolsky 2003). This was of great concern for Māori because te reo Māori is the vehicle by which thoughts, customs, desires, histories, and knowledge are communicated (Harlow 1993). Harlow (1993) further argued that a people without their own language have no power or unique identity. Sentiments about the importance of te reo Māori to Māori are encapsulated in this well-known quote from prominent Northland Māori elder Sir James Henare:

Ko te reo te mauri o te mana Māori

The language is the core of our Māori culture and prestige. (Waitangi Tribunal 1986, p. 53)

Without a significant population base anywhere else in the world, Māori people would lose one of their taonga (treasure), the vehicle of their culture, if te reo Māori was no longer to be spoken in Aotearoa New Zealand (Waite 1992). For Māori, the revival and then maintenance of te reo Māori is a critical language planning goal. With te reo Māori lying at the heart of Māori culture, Durie (1997) argued that Māori initiatives aimed at language recovery are not merely instrumental efforts to revive a language for day-to-day communication, but more importantly fulfil psychological needs central to the wellbeing of Māori individuals and groups.

In the political context, the change in status in the late 1970s of the Māori language galvanised groups such as those involved in broadcasting, health, education, and Nga Tamatoa ${ }^{1}$ to demand a greater role for Māori language in the government and various other public institutions (Walker 1987). As a consequence of increased lobbying by Māori communities and the release of the 1986 Waitangi Tribunal's ${ }^{2}$ report on the status of Māori Language, one of the government's responses was to pass the Māori Language Act in 1987, declaring Māori to be an official language.

Concurrent to the macro-level changes in the status of Māori language at the national level, there was a wave of grassroots initiatives to ensure the survival of

\footnotetext{
${ }^{1}$ Nga Tamatoa (translation The Warriors) was an activist group that operated in the 1970s to fight racial discrimination, confront injustices, and promote Māori rights.

${ }^{2}$ The Waitangi Tribunal was established in 1975 by the Treaty of Waitangi Act 1975 . The Tribunal is a permanent commission of inquiry charged with making recommendations on claims brought by Māori relating to actions or omissions of the Crown which breach the promises made in the Treaty of Waitangi signed in 1840 between the Crown and Māori the Indigenous people. For further details refer to http:// www.waitangi-tribunal.govt.nz/about/intro.asp
} 
Māori language (Reedy 2000). One of these initiatives was the development by Māori of a range of Māori-medium schooling options. The poor response by state schools to Māori language revitilisation efforts prompted groups of Māori, from 1985, to establish kura kaupapa Māori (Māori-medium primary schools), initially outside the state education system (Smith 1997). When Kura kaupapa Māori became state funded, they were required to implement state mandated curriculum, which at this time were written in English. A timeline of major developments in regard to language revitalisation and mathematics in te reo Māori is illustrated in Fig. 1 taken from Meaney et al. (2011). The diagram represents how different influences were operating at the same time, which then combined to affect later decisions.

In 1984, and thus at a similar time to Māori language revitalisation efforts, a neoliberal transformation began in New Zealand, with a raft of reforms, particularly in regard to how state institutions, including education, were to be structured and managed (Olssen et al. 2004). The neo-liberal ideology with an emphasis on individual choice, freedom of markets, and economic efficiency saw a reduced state bureaucracy that decentralised, privatised, and corporatised many of the state's operations. These policies also had an impact on curriculum development in many countries (Apple 1995; Howard and Thomas 2000). The Tomorrow's School legislation (Lange 1988) devolved responsibility for providing education to local communities under a charter system. As well, some of the functions previously carried out by a large Department of Education, including curriculum development, were contracted to external providers. However, this legislation mandated state control of curriculum development and implementation as a means of ensuring schools were accountable (Codd 1995). National curriculum development was to be one of the new Ministry of Education's goals for the 1990s.

\section{Walker's model of curriculum development}

In order to better understand how Māori used the two iterations of the curriculum development process to meet their aspirations to revitalise their language, it was important to identify how opportunities arose for them. Therefore, we have used Walker's (1971) model of curriculum development because in it curriculum development is perceived as a political activity, based on the ideologies of the people involved. Unlike other models (see Posner 1988), Walker's model is descriptive, rather than prescriptive, which, given that we were analysing a process that had already occurred, seemed valuable. Figure 2 provides a diagram of this model.

The model has three interconnected stages: the development platform, the deliberation stage, and the curriculum design. At each stage, people are involved in different kinds of activities and often motivated by differing agendas. In the first level, the platform, curriculum developers are involved in reflection about the assumptions that they bring to the curriculum development process.

The curriculum developer ... could not begin without some notion of what is possible and desirable educationally. The system of beliefs and values that the curriculum developer brings to his task and that guide the development of the curriculum is what I call the curriculum's platform. The word "platform" is 


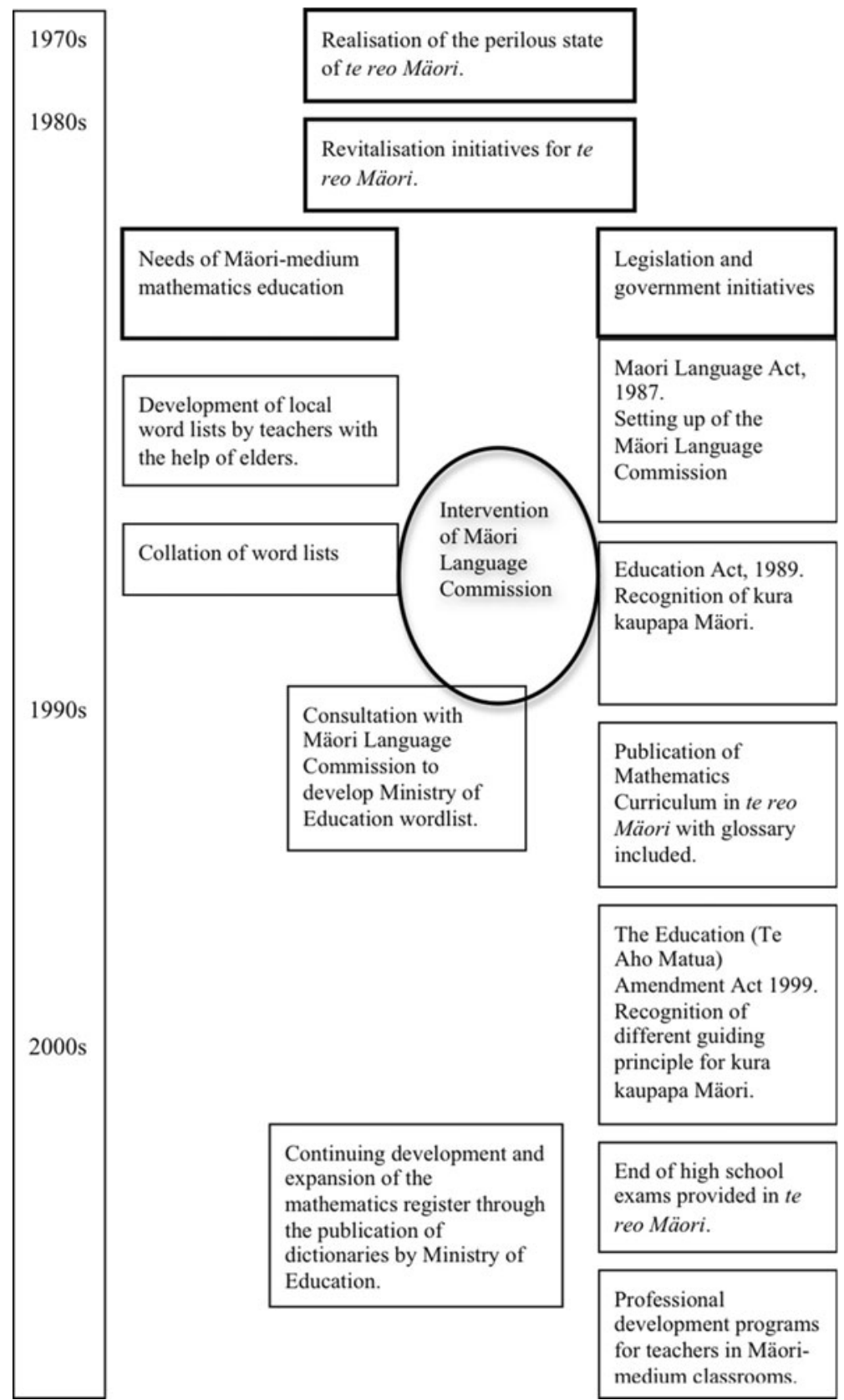

Fig. 1 An overview of the policies affecting the development of mathematics teaching in te reo Mãori (adapted from Meaney et al. 2011)

meant to suggest both a political platform and something to stand on. The platform includes an idea of what is and a vision of what ought to be, and these guide the curriculum developer in determining what he should do to realize his vision. (Walker 1971, p. 52) 


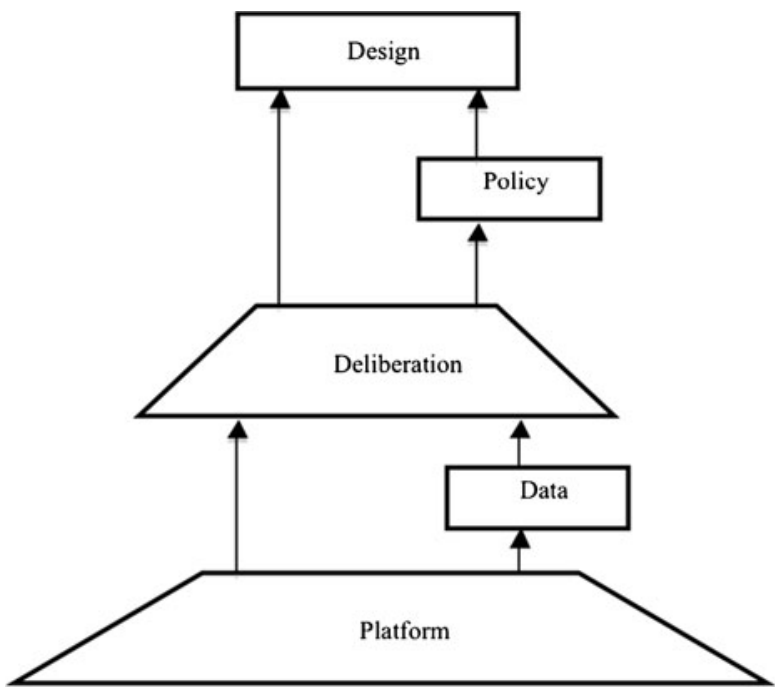

Fig. 2 A schematic diagram of the main components of the naturalistic model (from Walker 1971, p. 58)

At the deliberation stage, the developers interact and in so doing:

defend their own platform statements and push "spur of the moment" ideas ... [the deliberation phase] is a complex randomised set of interactions that eventually achieves an enormous amount of background work before the actual curriculum is designed. (Print 1993, p. 76)

Walker (1971) described the curriculum design as "the choices that enter into its creation" (p. 53). Rather than a product itself, the design is the set of decisions made to produce that product. However, "a curriculum's implicit design can never be completely specified in this mode of representation because the number of decisions, implicit and explicit, that underlie a project's materials is impossibly large" (p. 54). Curriculum developers' activity at this level is both to make the decisions and also to reflect on them.

Although allowing different points of view to be integrated in the deliberation phase (see Meaney 2001), Walker's (1971) model does not recognise the power relationships that exist between the various actors in the curriculum development process (McMurchy-Pilkington 2004a). Therefore in using this model, we have had to consider how these power relationships affected the curriculum development process and ultimately the linguistic issues. Codd's (1995) materialist model is useful here as it acknowledges that power can be mediated between actors driven by their ideological assumptions at the platform level.

In the next sections, we outline how the ideologies of the main actors influenced both curriculum development processes, which produced contested curriculum platforms that allowed Māori to ensure that their aims for language revitalisation were included. The main actors in the development of curriculum were the Ministry of Education and its agents, and Māori educationalists and the communities who they represented and consulted. We begin by examining the development of the first 
national curriculum for Māori-medium schools in the 1990s before contrasting this process with the process for revising it in the 2000 s.

\section{Phase one - national curriculum development}

The platform

In the early 1990s as an outcome of the changed macro-level education system, mathematics was the first curriculum area to have a new policy document developed (NZ Ministry of Education 1992a). Initially, no policy consideration was given to the needs of schools teaching in the medium of Māori, who at this time were mostly preparing their lessons using English-medium curricula and resources. This lack of consideration caused considerable consternation in the Māori community (Trinick 1997). As Considine (1994) argued, policy makers frequently fail to acknowledge that policy work requires a certain level of authority, power, and influence by groups of policy actors, including individuals and agencies who use available public institutions, such as education, to articulate and express the things they value. Therefore, the interests of minority groups, such as Māori, are often marginalised and reinterpreted to conform to preconceived notions about what is good for mainstream education.

As a result of concerns and intense lobbying by Māori (Ohia 1993a), somewhat belatedly, a parallel document for Māori-medium schooling was mooted. While on one level this acquiescence was surprising because the state had previously provided minimal support to language revitalisation efforts, the desire to develop a literate (in English) and numerate society was the goal of Aotearoa New Zealand education system, particularly in the latter stages of the 20 th century. This was when New Zealand's education system and curricula were reformed to respond to an economic climate of competitive and complex overseas markets (O'Neill 2005), including the need for a knowledge society (Humpage 2006). Therefore the government's goal of developing a numerate society could not exclude Maori-medium schooling, without being seen as reneging on its own commitments (Trinick forthcoming 2013). Māori recognised how they could use the government's agenda to achieve their own aims of language revitalisation and as well as the potential to increase their children's participation in mathematics and to improve Māori teachers' knowledge and skills. For example, Ohia (1993b) linked public statements that officially recognised the poor teaching of mathematics to Māori students with the then Minister of Education's need to agree to produce a Māori mathematics curriculum.

At the beginning of the process, both the government and Māori saw the writing of a new mathematics curriculum, Pāngarau (NZ Ministry of Education 1996), as an opportunity to turn their ideologies into tangible products. When the English-medium and Māori-medium curricula were developed, the Ministry of Education as the agent of the government, and in particular the Minister, had specific conceptions about how the curriculum development process would be undertaken and what the finished curricula would look like. These were enshrined in contractual agreements that the 
Māori Project Coordinator was required to sign before the project began. This can be seen in the following statements that come from Schedule A in the expressions of interest contract for developing the Māori mathematics curriculum:

The contractor will develop [a] draft curriculum document[s] in te reo Māori for New Zealand schools which:

- ... is parallel to the recently published curriculum statement Mathematics in the New Zealand Curriculum;

- maintains the achievement objectives, of the recently published curriculum statement Mathematics in the New Zealand Curriculum (New Zealand Ministry of Education 1992b, p. 8).

Contract conditions and the curriculum development processes established by the Ministry of Education were designed to ensure that the curriculum would be produced through the selection of the most appropriate contractors - those who were able to follow instructions - using cost-effective means. These conditions and processes were based on Ministry of Education understandings of how to make schools accountable to the government and the building of human capital. The processes also ensured that control remained with the Ministry of Education, through its mandated authority as a state institution, and reinforced the unequal power relationships between it and the Māori developers.

Although the Minister of Education consented to the development of a curriculum written in the medium of Māori, it had to be essentially a translation (Barton and Fairhall 1995). Nevertheless, as McMurchy-Pilkington (2004a) noted, the final goal for Māori was not necessarily a Māori-medium mathematics curriculum, but rather to take advantage of opportunities to co-opt the development of a Māori-medium mathematics curriculum to serve their community's linguistic needs, including the development of a Māori-medium mathematics register. Ohia (1995), in writing about the Māori Mathematics Movement (MMM), described the writing of the Māori mathematics curriculum in these terms:

The MMM is only ten or so years old, and already much has been accomplished. With the Government's support, the Māori mathematics curriculum statement has been written. An increasing number of mathematics glossary and concepts have been translated into Māori either by resurrecting traditional words which are no longer in general use, and which parallel the targeted mathematical content and skill, or by transliteration. This will continue as long as necessary. (p. 34)

The subsequent publication of the Māori-medium mathematics curriculum, Pāngarau (NZ Ministry of Education 1996), was the result of contestation between the state with an economic imperative and Māori educationalists, who were motivated by a desire for cultural and linguistic renaissance and a social justice imperative.

Curriculum deliberations

At the curriculum deliberation stage, the different actors had to defend their positions against those of the others. It is through interactions with each other that the 
background to the curriculum design becomes apparent. Therefore how the interactions were managed is important as it sets up whose position has more likelihood of being accepted.

With Pāngarau being the first national curriculum for Māori-medium schools to be contracted out, new models of engagement had to be created. For the first time, Māori educationalists were given some authority, however limited, to develop Māori-medium state curricula. Nevertheless, the state, via its agency the Ministry of Education, expected to control this development through its contractual obligations. As Openshaw (1996/1997) stated in regards to the development of the subsequent social studies curriculum, the hierarchical nature of the contract system limited the financial support for consultation. On the other hand, the Māori language community wanted to engage directly with the curriculum developers (McMurchy-Pilkington 2004b). Mediating between the government and the community were the curriculum developers, who were generally proponents of Māori language revitalisation and also part of the Māori community. As such they acknowledged their need to work cooperatively with their elders and Māori communities to modernise the Māori language. The development of a national curriculum for years 1-13 required a considerable expansion of mathematics terms for use in the upper-secondary school. This not only included the specialised mathematics terms such as hyperbola (püwerewere), but also the learning process terms, which encouraged children (and teachers) to communicate mathematically. One of the Māori writers, when interviewed in 2000 about the process, stated:

Each person had to have a reference group but in the Māori world your reference group means your whānau [family]. .... The Pakeha [European] process was adapted [that is, changed by us Māori curriculum writers] to very much a Māori process ... the Māori process came into play and proved to be effective and to be really valuable.

Another writer stated:

We did have frustrations but we managed to clear [these] up at some point by going around the systems and I think that's what's going to happen. The whole idea is this New Right separation and implementation stuff was really stupid for Māori network stuff, [Māori are] too intimately known to each other [and so talk and consult with each other anyway].

Each meeting of the Pāngarau curriculum development group, over the 18month curriculum development period, brought up new mathematical terms or concepts that needed developing in Māori, and this slowed the writing process considerably (Barton et al. 1998). Therefore, in order for the Pāngarau curriculum to be written, the state agreed to fund a series of consultation meetings with the various key stakeholder groups to consider the appropriateness of the Pāngarau corpus of terms. After considerable negotiation, a renegotiated contract was agreed to that allowed for a longer development timeframe as well as additional funding for consultation throughout the country with iwi (tribal) groups on linguistic issues. However, the timeline for completing the process 
remained a source of tension, as one of the Māori Policy Advisory group members and one of the Māori writers recalled.

It was decided by the Ministry that it would be a pāngarau [mathematics] document and it's got to be done within the timeframe. I think it's completely true and fair comment that there wasn't at that time, and I don't think there still has been enough debate about what we mean by pāngarau, that is mathematics, and how do you teach it and all those things. (Māori Policy Advisory group member)

We had a timeline to work with and so we came up with a compromise at the end of the day. (Māori Writer)

Further accountability was imposed on the Māori developers with the requirement that the newly coined terms had to be approved by the Māori Language Commission, a state agency. In 1987, the Māori Language Act was passed, declaring te reo Mãori to be an official language of New Zealand and provided for the establishment of Te Taura Whiri (Māori Language Commission). Te Taura Whiri was modelled on language academies in countries with a strong national language (May 2003), for example the Académie française in France. These language commissions have similar goals, including promoting the status and terminology development of their respective languages. Te Taura Whiri played a key role in the establishment of the norms of codification of the lexicon for schooling, including the purging of transliterated terms. These were English mathematical terms that had been given Māori pronunciation and spelling (Trinick forthcoming 2013). Transliterations purged included numa (number), kaute (count), and whika (from figure). The traditional term tau was adopted for number, and all the number-related words became prefixed with tau, so tatau became count, taurea to multiply (tau-number, rea-muliply). However, as noted by Fairhall (1993), some terms were being criticised almost as soon as they were coined:

Fortunately for the mathematics teacher the Māori Language Commission has produced a proposed word list. It is an invaluable if imperfect resource. Some words are cumbersome, others are of doubtful application. The grammatical status of a few words has been transmuted. (p. 120).

At the heart of a number of these interactions was the issue of trust or lack of it. The Ministry of Education had a poor history of supporting language revival, and Māori educationalists were new to the process of national curriculum development. At the curriculum deliberation stage, both groups learnt to make accommodations, whilst also adhering to the ideals that were important to them. The Ministry of Education exercised its control through the use of contracts but, when the Māori writers showed that they could not produce the required outcome without further financial support for consultations, the Ministry was forced to renegotiate the contractual arrangements. These tensions pervaded the context and the process of the curriculum development and influenced the curriculum design. 
Curriculum design

The design stage is about the decisions made when producing the actual curriculum. In regards to the Māori-medium curriculum the decision-making process was complicated by the fact that the English version of the mathematics curriculum document was completed in 1992 (NZ Ministry of Education 1992a). The Ministry of Education's agenda in the 1990s seemed to indicate reluctance to let the Māori documents be anything but versions of the Englishmedium curricula. Trinick (1997) suggested that more might have been achieved if the English and Māori versions had been written simultaneously.

Many decisions made during the development of the English-medium curriculum had to be accepted by the Māori curriculum writers. Some of these decisions were that the curriculum had to have the same achievement objectives and mathematical strands and had to be based on eight levels of progression, which was a structure not supported by educational research (Personal communication, English-medium curriculum Lead Writer, 2002). Therefore, the decision-making process for the first Māori-medium curriculum development was constrained by the ideology of the curriculum writers for the Englishmedium curriculum, guided by the Minister for Education. This ideology provided the parameters for the mathematics curriculum development process and thus the Māori-medium curriculum design, as outlined by one of the Minister's Advisory Group.

Now the fact that they [Māori writers] were told okay you've got to use the same sort of learning objectives, that sort of thing, that's the compromise you make in the political process but that's small compared with not having one at all.

However, some of the ideologies of the English-medium writers supported the language revitalisation aspirations of Māori. For example, constructivist theories of learning and mathematics teaching and learning in the late 1980s and 1990s had moved away from mechanical views of mathematics, to those with an emphasis on problem solving, understanding, and communicating mathematically with others. Consequently, an emphasis on mathematical communication was included in the 1995 Māori-medium curriculum document and in later professional development projects, such as Poutama Tau (Christensen 2003).

Although the Ministry of Education had controlled the development of Pāngarau, Trinick (1997, 2013) suggested that the outcome as well as the development process did support language revitalisation goals. During the curriculum work, the curriculum development group was confronted continuously with linguistic issues, in the writing group meetings, in special meetings to develop a glossary for the curriculum, and in the many reference group meetings held to discuss the ongoing development (Trinick 1997). The consultation meetings to standardise the terms in the Māori language resulted in some terms being accepted and others rejected. Consultation with Māori groups and $i w i$ also supported the general acceptance of the standardised corpus of terms by most of the Māori-medium education community. Therefore, the mathematics register development could be considered as a bottom-up approach rather 
than top-down policy, even though final approval had to be granted by the Mâori Language Commission. While the Ministry of Education support was inadequate to address all the challenges of teaching mathematics in Māori, a result of these initiatives was that terminology and register development accelerated and became more systematic and planned (Christensen 2003). This contributed to the teaching of mathematics in the medium of Māori to higher levels of schooling, thus providing another opportunity to elaborate the language. By concentrating on the development of the mathematics register as an aim for the curriculum development process, Māori managed to considerably expand the mathematics lexicon and mathematics register, which made a significant contribution to their language revitalisation goals.

Some examples of how the language was expanded included adding prefixes or suffixes to a base, stem, or root to form a new word. One of the common prefixes in Māori used extensively in maths is whaka. Rūna traditionally meant to "pare down" or "reduce." Adding the prefix whaka made whakarūnā to "simplify," as in "simplify the fraction $\frac{4}{12}$ " (it becomes $\frac{1}{3}$ ) (Trinick 2013 forthcoming). Two common suffixes in te reo Māori are the passive suffix and the nominal suffix. Wehe (divide) can become wehea (divided - passive), and wehenga (division - nominal).

The decision to accept the Ministry of Education's requirement that the structure of the curriculum be the same also enabled Māori to co-opt the implementation process to further support their language revitalisation goals. With the implementation of the Māori curriculum being a requirement under government legislation, the government through its agencies such as the Ministry of Education were obliged to support teachers and schools through a range of initiatives, including professional development and the publication of resources to support teaching and learning. Ohia (1995b) was representative of Māori beliefs that this would happen:

Presently the Maori mathematics curriculum have general statements which need more detail in order for present and intending teachers to take on the subject. Mathematicians who are supportive of the goals and objectives of the M[aori] M[athematics] M[movement] need to come together with Maori language and culture experts to link the mathematical content, skills and attitudes to the Maori world. (p. 35)

Trinick (1997) stated that the writing of the curriculum "legitimised the teaching of mathematics in Māori, ... led to teacher, advisor and resource teacher of Māori professional development ... that suited their specific needs, ... [and] many Māori were involved in mathematics education debate" (p. 36).

The determination by Māori to revitalise their language saw them take advantage of the opportunities provided in the development process. Thus the process was an enabling one, even within the heavy constraints placed upon Māori by the state (McMurchy-Pilkington 2008). Similarly, in the rewriting of the curriculum in the $2000 \mathrm{~s}$, the process that determined what decisions could be made by which stakeholders affected the actual design. Both the government and Māori worked from their own ideologies, although by this time both sets of ideologies had been re-shaped by the experience of developing this first Māorimedium curriculum. 


\section{Phase two - curriculum revision}

As part of the curriculum development discussions in the 1990s, the government agreed that a revision of both Māori- and English-medium versions of the mathematics curriculum would take place in about 10 years. In 2003, a group of Māori which was inclusive of elders and community representation was convened by the Ministry of Education to develop a philosophical base for the overarching framework, which bound all the learning areas together. This framework was absent in the 1990s' development, when each of the seven curricula statements was developed in isolation (McMurchy-Pilkington 2004b). The Māori group involved in developing the overarching framework continued to see a need to support the Māori language development of learners and teachers (Christensen 2003), and it was agreed that a Māori language strand would be integral to each of the mathematics strands, and indeed to all of the curriculum areas (Trinick 2013).

As a consequence, the Māori-medium curriculum was completely revised in 2008. While the basic structure of the 1995 curriculum was maintained, the earlier restrictive requirements, for example, to be a translation of the English version, were removed. Although there was no requirement to retain the eight levels of progression, it was decided to retain these as Māori teachers had become used to working with them. The same was said about the eight levels for the other six Māori-medium curricula. For similar reasons the English-medium developers also decided to retain eight levels in their revised documents.

\section{Curriculum platform}

In the intervening years between the 1995 initial development and the 2008 revision there were a number of political and educational changes in Aotearoa New Zealand. The ideology of the New Zealand government had moved to a more inclusive, Third Way model.

The Third Way was a political philosophy that sought to resolve the ideological differences between liberalism and socialism; it combined neoliberalism with renewal of civil society and viewed the state as an enabler, promoted civic activism and endorsed engagement with the voluntary and community sector to address society's needs. The Third Way sought to mobilise citizens and communities, and was grounded in the belief that a strong economy and strong society, in which citizens possess both rights and responsibilities, were closely interconnected. (Haugh and Kitson 2007, p. 983)

An inclusive society, with greater participation of groups and a self-help philosophy, supports equal opportunity and universal access but ignores Indigenous rights, deeming these to be "privileges." Under this approach inclusiveness and social responsibility are emphasised while individualism, economic freedom, and globalisation are still on the agenda. Education becomes "central to the alignment of economic and social goals, thereby achieving the political purpose of creating a knowledge society with a strong focus on the global marketplace" (Codd 2005, p. 9). Citizen participation along with building individual and community capacity are assumed to increase productivity, 
capability, and wellbeing. The rhetoric focuses on the knowledge economy with the expectation that schools will produce citizens for a highly skilled workforce. Thus the development of national curricula occurred within a government framework that saw the need for Māori to be economic citizens rather than one that promoted Māori rights and revitalised Māori language. Māori aspirations for their children include both - they want their children to do well economically in the future but not at the expense of losing their language and their culture.

On the other hand, while the basic tenet of neo-liberal ideology lived on and underpinned the revision of the curricula in 2008, the capacity of Māori to develop Māori-medium curriculum had developed significantly over the 10 -year period. The Ministry of Education was more relaxed as a result and more accommodating of difference. Consequently, the prevailing discourse advanced by Māori, particularly the work of Durie (2001), was integrated into government policy. This approach argued that education should be consistent with the goal of enabling Māori to live as Māori (Durie 2001), which meant that Māori needed to have access to te ao Māori, the Māori world, which included language, culture, et cetera. At the same time, there had been a philosophical shift in the Māori communities who were now no longer satisfied with Maori-medium schooling focusing on "saving" Māori language alone; they also wanted academic achievement for their children (Meaney et al. 2011).

Sadly, the time of the revision, the pool of older native speakers available during the earlier process had diminished and this had some impact on curriculum deliberations and design. There was more involvement of a younger generation of speakers who had different views about changes to te reo Māori than the older speakers. There was less resistance in the younger generation of speakers to changing the meaning of traditional terms to accommodate a modernised mathematics meaning. In contrast, the older speakers had been less resistant to using transliterated terms in the earlier phase. In the 1990s, the rejection by the Māori Language Commission and second language speakers of some common transliterated words that have been part of the language since early contact with English has resulted in criticism by older fluent speakers. These speakers found it difficult to understand the language used by the younger generation, which incorporated the new vocabulary. One such difficulty has been the newly coined Māori terms for the months of the year and days of the week (Harlow, 2003). As the modern mathematics language becomes the norm in the media (Meaney et al. 2011), then the confusion around which terms are appropriate should disappear.

\section{Curriculum deliberations}

In the second iteration there was a need to better reflect a Māori world-view in the curriculum. Ironically, this was a Ministry of Education requirement that stood in stark contrast to the 1995 requirement to simply translate the English-medium version. However, deliberations amongst the Māori writers around how to do this took over 6 months of debate. This time, the deliberations were not so much between the Ministry of Education and Māori curriculum developers but between Māori themselves. The Ministry provided Māori with an opportunity to resolve differences in their own way and did not insist as they had in the 1990s on the Māori-medium curriculum replicating what had been decided for the English-medium curriculum. 
The second iteration saw structural differences. There was more emphasis on Māori language acquisition that was made explicit through a mathematical literacy strand alongside the mathematical content strands. More contextual exemplars were included to support both teacher and student understandings of the mathematics and more general Māori terms and expressions. These exemplars reflected traditional and contemporary contexts. Spatial understandings, for example, the relationship between space and time, and locating and measuring were stronger in reflecting Māori ways of seeing the world.

Nevertheless, it did seem that Māori had accepted much about what it was to learn mathematics from the English-medium system, perhaps because of the need for Māori students to achieve similar education results. As well, there were considerations that Māori learners would enter tertiary education and be confronted with Western mathematics concepts and so at the higher levels of school, students needed to operate fluently with Western mathematics. Acceptance of this need meant that discussions about what mathematics was or could be did not occur.

During the intervening years, a number of mathematics education initiatives had been introduced into Māori-medium schooling. An increased focus on numerical literacy was part of a comprehensive policy to raise achievement standards in numeracy and this culminated in the development of the Poutama Tau (Māorimedium Numeracy Professional Development) Project based on a number framework, indicating developmental stages for children (Christensen 2003). This framework along with other key ideas had become part of established classroom practices and was incorporated into the revised curriculum.

Therefore in this iteration of the curriculum, jostling for control of the process that produced the background for the design decisions did not occur in the same way. An understanding from the first iteration that both the government's aim to produce economically viable citizens, accepted as important by most Māori parents, and Māori community aims for language revitalisation could be achieved simultaneously alleviated many of the tensions experienced in the 1990s. Instead Māori had an opportunity to identify and then resolve background issues themselves, which ironically resulted in their adopting similar solutions to those of the English-medium curriculum writers.

\section{Curriculum design}

With the main actors in general agreement about the background to the curriculum, there was more focus on the decisions that had to be made in order to produce the mathematics component of the curriculum. Similar to the situation in the 1990s, many of these decisions were about language development, although the actual decisions themselves were somewhat different.

By the time of the 2008 curriculum revision, the standardised corpus of terms that had been developed for the 1995 curricula was fairly entrenched in classroom practice. Nevertheless, work to support the implementation of the 1995 curriculum had continued through resource development, teacher professional learning programmes such as Poutama Tau, and considerations of assessment issues, such as assessment of senior students' work. Nearly every kind of issue resulted in considerations about new te reo Māori needs and suggested new vocabulary, or a 
revised term for existing vocabulary. Increased classroom use and increased sophistication of language used in the teaching and learning of Pannarau resulted in the corpus of mathematics terms and the mathematics register being expanded.

Research in Māori-medium mathematics education also highlighted that features of the mathematics register proved challenging to the learners (Meaney et al. 2011). As many students in Māori-medium are second-language speakers, learning the mathematics register may be requisite to understanding the specific content or to academic development in general. Māori teachers and academics were coming to an understanding that the mathematics register involves not just the learning of technical terms but an understanding of how to add "further layers of meaning for the terms and expressions they [the children] already know" (Meaney et al. 2011, p. 199). Research also highlighted the key role of teachers in modelling the language that is needed to support students' acquisition of mathematics language (Meaney and Irwin 2005).

Collectively this research pointed toward the need for an explicit Māori-medium literacy strand in the revised curriculum along with the general content strands to address the linguistic issues described above. With the pool of native speakers reduced and most Māori teachers being second-language learners, the curriculum writing group agreed that general competency to use and teach Māori language needed to be built up alongside knowledge of the more technical mathematics vocabulary.

During the design stage the question "Who is this curriculum for?" became prominent. Over the years a number of different Māori-medium schooling options had emerged, including tribal schools. Māori iwi (tribes) aspire to teach their tribal knowledge and dialects so they want to have their contexts reflected in the curriculum. An outcome of the decision deliberations was that the national curriculum explicitly required schools to develop a localised curriculum that supported the aspirations of the local community. However, the use of tribal dialects in the teaching of mathematics went against the sustained work of Māori mathematics educators to have a standardised mathematics register that was used consistently in Māori-medium schools across Aotearoa New Zealand. This tension is still being worked through. The tension can be seen in the following quote from a teacher who was discussing her situation teaching in a Māori-medium school away from her tribal area:

That's the thing that everyone needs to look at, is having their own expert people from their own iwi writing the things, not someone else. That's what I'd like, you know, that's what I think is the best thing to do. By going that standardized way, what's going to happen to the iwi language? It's going to just end up one plain, immersed, mainstream immersed - te whakaaro (that's the/my thinking). (Interview with Kura kaupapa Māori teacher, 2009)

The revised curricula, completed in 2008, were produced with an expectation that they would be less prescriptive, and more supportive of language acquisition and revitalization goals (Trinick 2013). These moves supported Māori parents' aspirations for their children to have greater proficiency in the Māori language, and to develop localised curriculum (Trinick 2013). By this time, the language of maths in te reo Māori had become normalised but the language of teaching and learning needed to become more integral to the teaching and learning of mathematics. Extensive work had been carried out in refining the mathematics register, including revisiting some of 
the earlier terms to ascertain whether they were the best choice to support mathematics language and concept development in second-language learners (Meaney, et al. 2011).

As had been the case in the first round of curriculum development, Māori have been able to take advantage of opportunities to further their own aspirations. Their aspirations were supported by the implementation of the government's ideology, which under a Third Way approach had become more relaxed towards difference. However different views are more evident amongst Māori communities and stakeholders as the range of Māori-medium schooling has increased (Trinick 2013).

\section{Conclusion}

It was somewhat fortuitous that the curriculum reform process implemented by successive New Zealand governments supported the goals of language revitalisation. Both curriculum development processes allowed for the development of the mathematics language in te reo Màori that was needed for the teaching of mathematics, professional development for teachers, and the subsequent production of resources in the Māori language. The government's goals were about education generally and invoked neo-liberal ideologies about public choice. On the other hand, Māori revivalists also wanted to use the curriculum development process to revive Māori language and culture. Although the sets of aims, for both sets of stakeholders, remained similar during the two phases of development processes, there were differences in how they manifested themselves in deliberations and the actual design of the curricula.

We argue that the authority embedded in the Ministry of Education as the primary state agency allowed it to maintain a firm grip of the curriculum development process through its control over the funding, decision making, and the content, including determination of what is mathematics (McMurchy-Pilkington 2008). Some decisions were not open for discussion because of the authority of the Ministry of Education. However, the government's ideologies of public choice, which resulted in state funding of private schools, contrasted with state control and accountability. The need for public choice resulted in the government agency, in this case the Ministry of Education, responding to the demands of Māori-immersion education sector.

Despite contesting the process and in some cases actually subverting it to ensure changes were accepted, Māori curriculum developers' agency was constrained. The initial curriculum development was restricted because of the rules set by the Ministry for what the curriculum should look like. In contrast, the underpinning neo-liberal ideology that fosters public choice and freedom of individuals encouraged Māori agency in the pursuit of their revitalisation aspirations such that they were not merely passive participants in the process. Their deliberations contributed to the curriculum design.

Thus, although Walker's model (1971) suggested that the design is a result of the deliberations, the decisions about the shape of the curriculum actually influenced what kind of deliberations could occur. Similarly, the deliberations of those involved can influence at the platform level their reflections on the beliefs, values, and aspirations that they hold about curriculum. We perceive that the arrows on the model 
at each stage need to be two-directional to reflect this, which is in line with Codd's (1995) materialist model. There is always a political and cultural context, argues Codd (1995), that can influence interactions and decisions at each level. This reformulating of the influences on each stage of the model has implications for those doing curriculum development in other contexts. It is not enough in analysis to concentrate on each stage of the development and move on to the next, as curriculum development is not linear. Rather there are two-way fluctuations and flows of power that can lead to contestation and contribute to the eventual shape of the curriculum policy document.

In the first round of curriculum development the areas for discussion were restricted because the recognition of the right for Māori to be part of the discussion was not acknowledged until after the English version was almost completed. Rather than reject the opportunity for this restricted curriculum development altogether, Māori took advantage of the ideological underpinnings to further their aspirations to increase, elaborate on, and standardise the mathematics register. At times this meant that there was contestation of the process and the curriculum design, by both the Māori developers and the Ministry of Education officials. At other times there was accommodation on both sides to achieve the outcomes, although usually to meet different agendas. Consultation meetings around the country meant that older native speakers could interact with mathematics teachers to discuss the mathematical terms suggested by the Māori curriculum writers and the Māori Language Commission. Māori also recognised that the production and acceptance of a state-mandated curriculum meant that the state would be required to support its implementation. Consequently professional development programs and development of resources led to further expansion of the mathematics language.

In the later rewriting of the curriculum, the only requirement was that the eight levels of learning progress were retained. At this time, the developers of the revised curriculum were able to use their agency to further promote language revival goals. The Ministry of Education accepted this goal, because of its own ideologies to develop a numerate society, and in spite of its need to hold teachers and schools more accountable. These competing goals were now seen as commensurate, thus there was less need for contested deliberations between Ministry of Education officials, and Māori educationalists and Māori communities. However important linguistic debates regarding issues like standardisation and iwi dialects are still ongoing.

In this paper, we provide historical and political background for Māori who will be involved in the next iteration of the Māori-medium mathematics curriculum. These implications can inform other Indigenous or marginalised groups about how mainstream process can provide opportunities for their own agendas to be implemented into education practices. Processes such as curriculum development are neither uncontested, nor linear. The process described in this paper shows how the bringing together of different agendas within neo-liberal philosophy can result in some groups that appear to be marginalised being able to make use of opportunities to achieve their own aims.

In future iterations of curriculum development in Aotearoa New Zealand, we suggest that the language of instruction be discussed because it can stimulate communities to access opportunities that are available to them to revitalise their language. 
Alongside consideration of framing a curriculum that reflects Indigenous ways of thinking, language planning must take into account the development of a corpus of terms relevant to the subject and processes. Debates also need to take place about standardisation of terms and the place of dialectical and tribal differences.

Acknowledgments An earlier version of this paper was presented at Topic Study Group 32 Curriculum Development at ICME12 in July 2012, Seoul, Korea. Much of the data for the first iteration of Panngarau came from McMurchy-Pilkington's thesis that was accepted in 2004. Full details are provided in the reference list.

\section{References}

Apple, M. (1995). Taking power seriously: New directions in equity in mathematics education and beyond. In W. G. Secada, E. Fennema, \& L. B. Adajain (Eds.), New directions for equity in mathematics education (pp. 329-348). Cambridge: Cambridge University Press.

Barton, B., \& Fairhall, U. (1995). Is mathematics a Trojan horse? In B. Barton \& U. Fairhall (Eds.), Mathematics in Māori mathematics. Mathematics Education Unit, Auckland: University of Auckland.

Barton, B., Fairhall, U., \& Trinick, T. (1998). Tikanga reo tatai: issues in the development of a Māori mathematics register. For the Learning of Mathematics, 18(1), 3-9.

Christensen, I. (2003). Exploring issues in mathematics education. Wellington: Ministry of Education.

Codd, J. (1995). Contractualism, contestability and choice: Capturing the language of educational reform in New Zealand. In J. Kenway (Ed.), Marketing education: Some critical issues (pp. 101-116). Victoria: Deakin University Press.

Codd, J. (2005). Education policy and the challenges of globalisation: Commercialisation or citizenship? In J. Codd \& K. Sullivan (Eds.), Education policy directions in Aotearoa New Zealand (pp. 3-18). Victoria: Thomson Dunmore Press.

Considine, M. (1994). Public policy: A critical approach. Melbourne: Macmillan Education Australia Pty.

Durie, M. (1997). Whaiora: Maori health development. Auckland: Oxford University Press.

Durie, M. (2001). A framework for considering Mãori educational advancement. Opening address to the Hui Taumata Mātauranga, Tūrangi/Taupō, New Zealand, 24 February.

Fairhall, U. (1993). Mathematics as a vehicle for the acquisition of Māori. In E. McKinley, P. Waiti, A. Begg, B. Bell, M. Biddulph, J. Carr, J. Chesney, \& J. Young Loveridge (Eds.), SAMEpapers (pp. 116123). Hamilton: Centre for Science, Mathematics and Technology Education Research, University of Waikato, New Zealand.

Fishman, J. A. (1991). Reversing language shift. Clevedon: Multilingual Matters.

Harlow, R. (1993). A science and mathematics terminology for Maori, SAMEpapers. Hamilton: Centre for Science, Mathematics and Technology Education Research, University of Waikato, New Zealand.

Harlow, R. (2003). Issues in Māori language planning and revitalisation. He puna Kōrero: Journal of Māori \& Pacific Development, 4(1), 32-43.

Haugh, H., \& Kitson, M. (2007). The third way and the third sector: New labour's economic policy and the social economy. Cambridge Journal of Economics, 31, 973-994.

Howard, J., \& Thomas, J. (2000). The politics of mathematics education 1996-1999. In K. Owens \& J. Mousley (Eds.), Mathematics education research in Australasia 1996-1999 (pp. 341-368). Sydney: Mathematics Education Research Group of Australasia.

Humpage, L. (2006). An 'inclusive' society: a 'leap forward' for Māori. New Zealand. Critical Social Policy, 26(1), 220-242.

Jahnke, A. (2012). The process of developing a syllabus: Reflections of a syllabus developer. Paper delivered at the 12th International Congress of Mathematics Education, Seoul, Korea, July 8-15, 2012. Available from: http://www.abc.net.au/unleashed/4055530.html.

Lange, D. (1988). Tomorrow's Schools: The reform of educational administration in New Zealand. Wellington: Government Printer.

McMurchy-Pilkington, C. (2004a). Pāngarau Māori medium mathematics curriculum: Empowerment or new hegemonic accord? Unpublished EdD thesis, University of Auckland, Auckland, New Zealand.

McMurchy-Pilkington, C. (2004b). He Arotakenga o ngā tuhinga e pā ana ki ngā Marautanga Māori. Auckland: University of Auckland Final report to the Ministry of Education. 
McMurchy-Pilkington, C. (2008). Indigenous people: emancipatory possibilities in curriculum development. Canadian Journal of Education, 31(3), 614-635.

May, S. (2003). Rearticulating the case for minority language rights. Current Issues in Language Planning, 4, 95-125.

Meaney, T. (2001). An ethnographic case study of a community-negotiated mathematics curriculum development project. Unpublished PhD thesis, University of Auckland, Auckland, New Zealand.

Meaney, T., Trinick, T., \& Fairhall, U. (2011). Collaborating to meet language challenges in Indigenous mathematics classrooms. New York: Springer.

Meaney, T., \& Irwin, K. C. (2005). Language used by students in mathematics for quantitative and numerical comparisons: NEMP Probe Study Report. Dunedin: EARU, University of Otago, New Zealand.

New Zealand Ministry of Education. (1992a). Mathematics in the New Zealand curriculum. Wellington: Learning Media.

New Zealand Ministry of Education (1992b). Mathematics in the New Zealand curriculum: Curriculum statement for Māori. In Agreement for curriculum development services (pp. 1-8). Wellington, New Zealand.

New Zealand Ministry of Education. (1996). Pāngarau i roto i te marautanga o Aotearoa. Te Whanganui ā Tara: Te Pou Taki Kōrero.

Ohia, M. (1993a). Kaua e whakamāorita noatia, engari whakaritea ki tō te Māori e hiahia ai: Don't translate it into Maori, but ensure it encapsulates the Maori needs and aspirations. In Te Puni Kokiri (Ed.), Pāngarau - Maori mathematics and education (pp. 1-6). Wellington: Te Puni Kokiri, Ministry of Maori Development.

Ohia, M. (1993b). Adapting mathematics to meet Maori needs and aspirations: An attempt to shift paradigms. In E. McKinley, P. Waiti, A. Begg, B. Bell, F. Biddulph, M. Carr, J. Chesney, \& J. Young Loveridge (Eds.), SAMEpapers (pp. 104-115). Hamilton: Centre for Science, Mathematics and Technology Education Research, University of Waikato, New Zealand.

Ohia, M. (1995). Maori and mathematics: What of the future? In B. Barton \& U. Fairhall (Eds.), Mathematics in Māori mathematics. Mathematics Education Unit, Auckland: University of Auckland, New Zealand.

Olssen, M., Codd, J., \& O’Neill, A. M. (2004). Education policy: Globalisation, citizenship, democracy. London: Sage.

O’Neill, A.-M. (2005). Individualism, enterprise culture and curriculum policy. In J. Codd \& K. Sullivan (Eds.), Education policy directions in Aotearoa New Zealand (pp. 71-86). Victoria: Thomson Dunmore Press.

Openshaw, R. (1996/1997). Social studies in the curriculum? Critical citizenship or crucial cop out? DELTA, 48(2), 159-172.

Posner, G. J. (1988). Models of curriculum planning. In L. E. Beyer \& M. W. Apple (Eds.), The curriculum: Problems, politics and possibilities (pp. 77-97). New York: State University of New York Press.

Print, M. (1993). Curriculum development and design. Sydney: Allen \& Unwin.

Reedy, T. (2000). Te Rēo Māori: the past 20 years and looking forward. Oceanic Linguistics, 39(1), 157-169.

Smith, G. H. (1990). The politics of reforming Maori education: the transforming potential of Kura Kaupapa Maori. In H. Lauder \& C. Wylie (Eds.), Towards successful schooling (pp. 73-88). London: Falmer Press.

Smith, G. H. (1997). The development of kaupapa Māori: Theory and praxis. Unpublished PhD thesis, University of Auckland, Auckland, New Zealand.

Spolsky, B. (2003). Language policy. Cambridge: Cambridge University Press.

Te Tahuhu o te Mātauranga. (2008). Te marautanga o Aotearoa. Whanganui a Tara: Te Pou Taki Kōrero.

Trinick, T. (1997). The development and implementation of the Pāngarau curriculum statement. Unpublished Master's thesis, University of Auckland. Auckland, New Zealand.

Trinick, T. (forthcoming 2013). Tensions and issues in the development of the mathematics register for Māori-medium schooling. Unpublished EdD Thesis, University of Waikato, Hamilton, New Zealand.

Tribunal, W. (1986). Report of the Waitangi Tribunal on the te reo Maori claim (Wai 11). Wellington: Waitangi Tribunal.

Waite, J. (1992). Aotearoa: Speaking for ourselves: A discussion on the development of a New Zealand languages policy: Part B: The issues. Wellington: Learning Media.

Walker, D. F. (1971). A naturalistic model for curriculum development. School Review, 80(1), 51-65.

Walker, R. (1987). Ngā tautohetohe: Years of anger. Auckland: Penguin. 